Review Articles

\title{
An Investigation into the Challenges and Opportunities Associated with the Application of Internet of Things (IoT) in the Agricultural Sector-A Review
}

\author{
Sarfraz Fayaz Khan and Mohammed Yusoof Ismail \\ Department of Management Information Systems, \\ College of Commerce and Business Administration, Dhofar University, Salalah, Sultanate of Oman
}

Article history

Received: 23-04-2017

Revised: 22-06-2017

Accepted: 15-08-2017

Corresponding author: Sarfraz Fayaz Khan

Department of Management Information Systems,

College of Commerce and Business Administration, Dhofar University,

Salalah, Sultanate of Oman

Email: ${ }^{1}$ skhan@du.edu.om ${ }^{2}$ mismail@du.edu.om

\begin{abstract}
Internet of things has acquired attention all over the globe. It has transformed the agricultural field and allowed farmers to compete with massive issues they face. The aim of this paper is to review the various challenges and opportunities associated with the applications of internet of things in agricultural sector. This research makes use of secondary sources that have been gathered from existing academic literature such as journals, books, articles, magazines, internet, newsletter, company publications and whitepapers. Applications reviewed in this research are about crop sensing, mapping and monitoring the croplands pattern, managing and controlling with the help of radio frequency identification and real-time monitoring of environment. Some of the challenges that were taken into consideration for reviewing the applications of internet of things are software complexity, security, lack of supporting infrastructure and technical skill requirement. Complexity in the software has to be rectified in order to support the IoT network. Therefore software must be developed as user-friendly for improving the farming, production and quality of the crop. Security is the major threat in the IoT applications. Security has to be enhanced through proper access control, data confidentiality and user authentication. Technical skill is required for farming to enhance the organizational abilities and to perform the farming functions, solving problems and more. Proper supporting infrastructure can be developed with proper internet availability and connectivity. Some of the opportunities were taken for reviewing the applications of internet of things are low power wireless sensor, better connectivity, operational efficiency and remote management.

Keywords: Internet of Things, Software Complexity, Lack of Supporting Infrastructure, Security, Technical Skill Requirement, Low Power Wireless Sensor, Remote Management, Better Connectivity and Operational Efficiency
\end{abstract}

\section{Introduction and Research Background}

Agriculture is referred as the basis of life for the human beings as it is considered as the main source of food grains and other raw materials. It plays a potential role in the economic growth of the country. Enhancement of agricultural sector through introduction of new technologies stands as one the biggest challenges for developing nations. Unfortunately, most of the farmers are still using the traditional farming methods resulting in low crops and fruits yielding. Spatiality, complexity, enormousness and dynamics are some of the characteristics of agricultural sector that affect the production and quality and it seems to be different for each and every crop. Environmental factor monitoring seems to be not enough and there are many factors affecting the productivity to a greater extent (Nandurkar et al., 2014). The farmland environment is very complicated system of ecology which may create the impact on the development of the economy. So, in order to provide the solutions for all the problems, it is necessary to develop an advance integrated system to 
take care of all factors influencing the productivity in each stage like cultivation, harvesting and storage of post harvesting. The Internet of Things (IoT) is referred as the network of network typically associated with large number of sensors connected through information and communication infrastructure to provide the value added services. It is one of the hot concepts emerged since the 1960s. It is referred as one of the hard-core technologies of the IT industry of the new generation (Cai, 2012). The ultimate aim of this IoT is to create the better world for human species, where the objects around us understand the comments and hence act accordingly without any instructions explicitly. IoT is highly on the rise and it has been observed to control areas and bring them completely under its influence. It has the tendency to obtain powerful computing tools via cloud computing. It is pointed as an intelligent technology which includes sensing, identification and intelligence. It can be used in pattern identification areas like sensing, collection and processing of the information and communication. Controlling of all these operations has attained through remote smart devices connected to the internet. Further the whole operations will be performed by means of interfacing sensors, Zigbee modules or Wi-Fi, camera with micro-controller and raspberry pi (Devi and Meenakumari, 2013). In this effect, microcontrollers, microprocessors, actuators and sensors are some of the physical devices which directly communicate with the internet. They work by using the gateway of IoT. This entire infrastructure is called as the infrastructure of IoT. The smart farm embedded with the systems of IoT is called as the connected farm as it could support the devices in a wide range from diverse device manufacturers of agricultural field. In this sense, the connected farms can provide more services of intelligent agriculture based on shared knowledge of the expert. At last, the IoT impact has given good results and it plays an efficient role to extend into latest technologies like grid and cloud computing in many different sectors. Finally, this paper also aims to investigate some challenges and opportunities associated with the IoT application in the agricultural field.

\section{Review of Literature}

\section{Usage of IoT in Various Agricultural Applications \\ Sensing of crop (Water, Moisture and Temperature)}

A study done by Bangera et al. (2016) examined the IoT based smart village. In smart farming, the content of moisture in the soil acts as the major factor to determine the growth of the plant. Soil moisture sensor is resistive sensor used to change the soil resistance between two probes that depends on content of water. Apart from these, temperature and humidity is one of the main environmental parameters worked with the climatic change, topography, types of soil and vegetation (Dursun and Ozden, 2011). Crop planting time, tile ring growth and winter safety are some of the processes which are closely related to the soil temperature. In this way, the temperature sensor has given the specific idea about the coolness and heat content variation in the soil. Sensor based automated irrigation system with IoT has been analyzed by Kansara et al. (2015). The temperature and humidity sensor senses the changes in temperature and humidity and it also has the tendency to give an interrupt signal to the micro-controller devices. A low cost internet of things network for contamination detection in drinking water systems using raspberry pi was analyzed by Anam and Devender (2015). The temperature of water can be measured by the water sensor when dipped into the water.

Kumar and Ravi (2016) studied about the automation of irrigation system based on Wi-Fi technology and IoT. The soil moisture sensor and temperature sensor has played an important role in developing an automation to supply water for irrigation system and home gardening in fields of farming. Cloud IoT based system of greenhouse monitoring has been investigated by Keerthi and Kodandaramaiah (2015). Temperature, light, relative humidity and soil moisture sensor have integrated to demonstrate the greenhouse monitoring system. Crop sensing has been done accurately by using the IoT and this has further created the positive impact on the agricultural field.

\section{Managing and Controlling (Use of RFID)}

A study done by Kang et al. (2015) examined an effect of IoT based electronic sow feeder on productivity of swine farms. Radio Frequency Identification (RFID) is commercial technology in the system of IoT. This technology has been applied in the raising industry by the IoT based production management systems. RFID tag has played a potential role to control the amount of feed. Tongke (2013) focused the study on the smart agriculture based on cloud computing and IoT. According to him, the RFID and IoT, has helped to build plant factory and it also plays an important role to realize the automatic control production in the agricultural sector. In fact, the RFID, sensor and GPS worked together for information sensing in the process of production. Sarkar and Chanagala (2016) surveyed IoT based digital agricultural monitoring system with their impact on optimal resource utilization. RFID has helped to build the device for the process of sensing the parameter in the agriculture and it further sends signal to the internet in an effective manner. In this effect, the IoT based RFID has improved the quality of agriculture products by managing and controlling the products. Barakat (2016) has pointed that the RFID's and GPS points can be embedded in agricultural field and it can benefit from the collected information they provide. 
Information collected through the devices can then be proceeding and the final results are used to perform an automated task via Wi-Fi connection (Buckely, 2006).

According to Zhao and Wang (2014), RFID tracing application with IoT has helped to manage and control the information in the supply chain value of agricultural products. IoT can make use of RFID technology for scanning EPC tags on the items and hence it has achieved the automatic identification and information sharing successfully. The authors also pointed out the RFID as the most critical technologies in the IoT. It can be also predicted that the RFID has used to achieve intelligent identification, monitoring, remote control and positioning in the agricultural production (Qin et al., 2015).

\section{Mapping and Monitoring the Croplands Pattern}

A study done by Jaishetty and Patil (2016) examined IoT sensor network based approach for agricultural field monitoring and control. The solution of remote monitoring has played a significant role to monitor in real time through some of the remote devices such as tablets and mobiles. Ultrasonic waves have been used with IoT to monitor the soil quality and levels of ground water in agricultural field. The optimal sensor methods of placement have used to monitor the environmental change and wireless sensor networks have played a potential role to monitor the patterns of cropland Table 1 . Parameswaran and Sivaprasath (2016) studied about arduino based smart drip irrigation system using IoT. Crop has continuously monitored by using PC host. LCD has also played an efficient role to improve the method of cultivation and hence it leads to better productivity effectively. System hardware associated with the IoT created the significant impact on monitoring and controlling system of smart agriculture. Channe et al. (2015) pointed that the real time monitoring properties of IoT has helped to maintain the health of soil intact by applying the required fertilizer amount. In fact, the analysis of soil moisture by sensor also has helped to apply water in necessary areas. Zigbee and GPS technologies also pave way to monitor the cropland pattern in an effective manner.

Automatic intelligent equipment and remote control production devices played an efficient role for farmers to monitor the farmland information without leaving home. In this effect, the agricultural IoT has related to some of the field such as weather monitoring, automatic greenhouse controlling, intelligent control system of planting industry, traceability of food safety, environmental monitoring etc (Wu et al., 2015). According to Paventhan (2013) IoT also has aimed to extend internet to distributed devices in large numbers by defining the communication protocols.

\section{Real-Time Monitoring of Environment (Using Wireless Technology)}

A study done by Pavana and Padma (2016) designed a low cost system for real time monitoring of water quality parameters in IoT environment. The IoT has the capability to revolutionize the water industry as more of the innovative technology has connected to web. The water quality monitoring through online mode has acquired much attention worldwide. Converging technologies for smart environments and integrated ecosystems of IoT has been investigated by Vermesan and Friess (2013). Monitoring of soil moisture, vibrations, density of earth to detect the dangerous spatterns in land conditions have been achieved by the wireless technology of IoT. In addition to these, the monitoring of variations of water level in dams, rivers and reservoirs are also analyzed using the IoT in an effective manner. Wine quality enhancing, green houses, half courses, meteorological station network and compost are also achieved in agricultural sector by using the wireless technology of IoT.

Advantech (2015) pointed out that the real-time remote monitoring and management has been achieved by the IoT wireless technologies successfully. In realtime monitoring system, the information can be remotely checked through mobile phones, computers etc. In this sense, the distributed systems, nutrients etc. across the greenhouses can also be managed in an efficient way (Li and Guo, 2014; Abdul Aziz et al., 2009). It also has provided different workers with different authority level. Getting real-time information through e-mail alerts and SMS are also achieved in the smart agriculture system. Greenhouse wireless network monitoring and management using internet of things has been analyzed by Jagdale and Mali (2016). The authors pointed that the wireless network technology has monitored the light intensity that was incident in the field greenhouse area. In fact, monitoring and controlling of green field environment has played an important role in production of crops and this has further maximized the activity of photosynthesis. Better infield monitoring of cropland has achieved only by means of IoT wireless technology when compared to other technologies (Doknic, 2014).

\section{Challenges of Applying IoT in Agriculture}

\section{Software Complexity}

A study done by Soumyalatha and Hegde (2015) examined the application, issues, challenges and architecture of IoT. Scalability, self-configuration, interoperability, complexity of software, storage volume, interpretation of data, security and personal privacy, fault tolerance and energy-optimized solutions are some of the challenges associated with the IoT (Perera et al., 2015; Borgohain et al., 2015; Whitmore et al., 2015; Bandyopadhyay and Sen, 2011). In fact, the software 
systems in smart objects work with minimal resources and the software infrastructure is needed support the network and hence it also required the server to support networks smart objects on the back ground.

A study done by Pande and Padwalkar (2014) examined the internet of things. The software complexity and data interpretation are referred as the main challenges of IoT in agricultural sector. The systems of software in smart objects should have to function with minimal resources as in the conventional embedded systems (Ashton, 2009). In fact, the fault tolerance also has possessed the great challenges and it requires redundancy on several levels depending on various conditions.

Balamurugan et al. (2016) studied about applying IoT to improve food and farming technology. Userfriendly software has paved the way for the big data for small farms with the creative usage. In particular, the software, actuators, sensors and technologies of energy harvesting are directly contributing to the IoT development (Guang et al., 2011). Software complexity, spatiality and dynamics are some of the factors which are affecting quality and production of crop in higher level (Venkataramana and Padmavathamma, 2012).

A study done by Madakkam et al. (2015) examined the Internet of Things (IoT). Hardware, middleware and presentation of software of IoT have the capability to create the negative impact on the agriculture (Jayavardhana et al., 2013). Patil et al (2012) has overviewed the internet of things and cloud computing for agriculture. Complexity, spatio-temporal variability and diversity are some of the characteristics features related to agriculture need to be considered in developing the right kinds of services. In addition to these, the actuators, sensors, software and location technology (GPS), wireless communication and RFID technology (Shao and Li, 2009) are some of the technologies which have contributed to the development of IoT in many sectors. In this sense, understanding and operating the software seems to be more complex in some of the sectors like agriculture.

\section{Security}

The study done by Mehta and Patel (2016) examined IoT based smart agriculture research opportunities and challenges. The IoT has connected with more devices together and it also has provided the decentralized energy points for malware creates a negative impact on the smart agriculture. It also has become the main challenge of IoT in agricultural sector. Less expensive devices which are in compromised locales are more subject to the process of tampering (Fangquan, 2012; Sun et al., 2008) In addition to these, more software layers, APIs, middleware integration and machine to machine communication are some of the terms which are creating the complexity and new risks of security in higher level.
Wang and Liu (2014) focused some of the application of IoT in agricultural means of production supply management. The internet of things application in the stage of agricultural product sale has reflected in the form of security, statistics and validity monitoring.

WEF (2015) analyzed industrial internet of things by unleashing the potential of connected products and services. Security and privacy of IoT has created both the positive and negative impact in agricultural sectors. The securities are raising an increased vulnerability to attacks, espionage and data breaches driven by increased sharing of data and connectivity (Osborn and Charlie, 2014; Elfrink, 2014; Shankland and Stephen, 2014). Finally, it can be predicted that the security and interoperability are referred as the two biggest hurdles of implementing the IoT in agricultural sectors.

Kumar and Patel (2014) have surveyed the internet of things with security and privacy issues. Front-end sensors and equipment, network and back-end of IT systems are referred as the security threats of IoT. Safety management of code resources and operator replacement are some of the terms associated with the back end of IT systems (Liu and Yang, 2011; Jiang and ShiWei, 2010; Zhou et al., 2012). In fact, the security of IoT system has some major standards such as access control, authentication of user, data confidentiality and anytime availability (Abomhara and Koein, 2014; Zhao and Ge, 2013). These are further associated with the back-end of IT systems also creates an impact on the development of agriculture.

Fernandes et al. (2016) have evaluated the internet of things with security challenges and future scope. They pointed that the confidentiality, integrity, availability and authentication are some of the factors which are linked with the security issues. Additionally, the common worms jumping, organized crime and cyber terrorism are some of the security threats associated with the IoT further create an impact on agricultural field (Farooq et al,., 2015; Roman et al., 2011a; 2013b).

\section{Technical Skill Requirement}

Chikaire et al. (2015) pointed that the capacity building is one of the essential key to survival of agricultural extension. The technical skill requirement is needed for farming and the lack of operating skills creates an impact on the overall performance in field of agriculture. The capacity building has focused on enhancing the abilities of an organization to perform the functions of farming, solve problems and also deal with the need of development (Rivera, 2000).

Jacobs and Hart (2012) studied about the skill development in rural areas. Skill based technical change also has evolved to increase demand for high skilled labor across different working environment. Motor skills, cognitive skills and interactive skills are the three 
stages of skills demand for the operator in the farming. In this effect, the ability of education tends to be the primary problem for the farmers from adopting new practices and effective technologies.

Menon et al. (2012) have assessed the technical manpower requirements in agriculture sector in India. The technical manpower has expected to be requiring in a high number. This will continue to be insufficient during the horizon with time. The authors pointed that the technical manpower in sector of agriculture has played a vital role in achieving the self-sufficiency in the grain production of food (FCCI, 2007; Kao and Lee, 1998). In fact, there is a shortage of technical manpower in agriculture field at various levels especially related to IoT.

Podder and Kuntagod (2016) studied some smart services with designing internet of things solutions to aspire the smart nations. Most of the growing economies lack the resources of finance, manpower, skills related to technology and access to the latest technology necessary for strengthening the infrastructure. Interoperability, ensuring security of data and sourcing the required skills are some of the fundamental issues rising in emerging economies.

Rose et al. (2015) have overviewed the internet of things with several challenges. The scope of IoT challenges has not been unique to industrialized countries. Infrastructure readiness, incentives of market and investments, technical skill requirements and the resources of policy have been identified as some of the challenges linked with the IoT in many sectors. Interoperability has created the significant influence on the IoT with the economic impact beyond technical aspects.

\section{Lack of Supporting Infrastructure}

Bidua and Patel (2015) studied about internet of things and cloud computing for agriculture in India. Smart grid, traffic systems etc. have been identified to have supporting infrastructure which is far from being ready for internet of things in agricultural field (Yan-e, 2011; Channe et al., 2015; Bo and Wang, 2011). In fact, the IoT has offered the tremendous potential to innovate in the field of agriculture. In India, internet availability and connectivity seems to be the major challenge and adoption of IoT becomes difficult for farmers due to lack of supporting infrastructure.

Sharma et al. (2016) analyzed the technical assessment of IoT for Indian agricultural sector. Smart metering and smart grid infrastructure of IoT are lacking in the agricultural field. Furthermore, the infrastructure modernization cost and maintenance seems to be a great challenge of IoT in farming (Lee et al., 2013).

Pundir et al. (2016) analyzed the future directions and challenges of internet of things. Lack of information infrastructure facilities of IoT in farming has created the negative impact in productivity. The rural farming areas are not advanced in terms of overall infrastructures. In fact, the unanticipated resource of development has diminished the abilities of the individual to add new functionality related to core.

Roshan and Ray (2016) analyzed some of the challenges and risk to implement IoT in smart homes with respect to an Indian perspective. Smart power grid, smart drainage or system of sanitation, supply of smart water, are some of the supporting infrastructure which are far away from being ready to use in Indian agricultural area (Jin et al., 2014; Datta et al., 2014). In particular, the centralized infrastructure of IoT to support analytics have required in the agriculture field to attain the specific tasks (Gubbi et al., 2013).

\section{Opportunities Associated with the Application of IoT in Agriculture}

\section{Low Power Wireless Sensor}

A study done by Chen (2012) examined the challenges and opportunities of IoT. Low power wireless sensor is one of the main opportunities associated with the application of IoT. Low power sensors are needed replacement of battery over their lifetimes. The design of low power transmitter should be considered for low power sensor node and hence it attains the greatest impact in the agricultural sector. Low power wireless less sensor networking of IoT has achieved high success over other technologies (IEC, 2014; Sen, 2009). It has the capability to cover an area of only a small dozen meters. In this sense, the low energy consumption of sensors is act as the main key to support the independent battery powered devices in a longer flow. This has helped to reduce the cost of maintenance simultaneously. Anusha and Shobha (2015) analyzed the design and implementation of wireless sensor network for precision agriculture. Recently, low cost and low power wireless sensor technology seems to be well suited to replace wires as the medium of communication in most of the applications of agriculture (Gutierrez et al., 2014). More and Nighot (2016) has reviewed the wireless sensor network for agriculture. The advancement of wireless sensor networks and reduction of size has increased the WSN application chances in agricultural field. The wireless sensor has consumed low cost and it has the ability to withstand the resistance towards the current successively (Barath et al., 2016). The ability of data gathering and remote sensing are closely related to the low power wireless sensor.

\section{Better Connectivity}

Machine to machine is referred as the autonomous networking to connect large populations with efficient usage of energy. Better connectivity of IoT devices may 
achieve the efficient outcome in agricultural sector. Internet connectivity seems to be vital to the solutions of IoT. Wireless links have played an effective role in covering huge distances at reasonable costs (Miazi et al., 2016). Better internet connectivity has enabled to push the data onto the cloud and it also helps to visualize the data using the mobile and other electronic devices. IoT seems to be more popular and easy to use in almost every field (Raigonda et al., 2016; Domingo, 2012; Zhang et al., 2013). GSMA (2015) has analyzed the agricultural Machine to Machine (M2M) as a platform of expansion. Better connectivity of IoT has enhanced the sustainability of business in higher level. Cellular M2M, short-range (Wi-Fi, Zigbee and Ethernet), satellite and fixed networks and power line are some types of M2M connectivity significantly linked with IoT. In some areas, the lacks of distribution of channel and limited connectivity access have created an impact on the agriculture areas (OECD, 2016). M2M connectivity services have helped the farmers to improve the efficiency of farming operations. High bandwidth fiber connectivity also has enabled the communication with low latency which keeps the farming area more active.

\section{Operational Efficiency}

Operational efficiency has achieved the application of IoT and it can be called out by the enhanced usage of energy with effective infrastructure of IoT. The IoT power has tackled the issues of environment which lies in its ability to gather data through analytics. It also drives the smarter decisions about operational efficiency, strategy of business and the allocation of resources. The IoT has the opportunity to capture data which optimizes operational efficiency and reducing the impact of environment in a higher level (Wind, 2016). According to Schimek (2016), the IoT implementation has improved the analytics, efficiency and predictive maintenance. Sensor and wireless technologies of IoT has played a potential role to increase the efficiency and hence it provides an accessible vehicle network to its customers. Oracle (2015) pointed out that the agribusiness performance has been improved by using big data and IoT. The solutions of IoT and big data have improved forecasting and efficiency of an operation. It also leads to improved decision making. Timely scheduling equipment maintenance and minimizing the usage of energy has enabled the greater operational efficiency in agricultural sectors. In this effect, the operational efficiency of information and technology has often difficult to prove. Romeo (2016) analyzed the current status and trends enabling smart farming through the IoT. Low cost and high volume of sensor paves a way to attain the high operation efficiency in the farming area.

\section{Remote Management}

A study done by Yin (2017) examined the implementation of IoTs in agriculture industry in China. Alarm management, remote control and expert system are closely connected with each other as it has helped to attain the high production in the agriculture area. Realtime surveillance is referred as the main functions in the agricultural site. Remote monitoring of the crop growth process is also achieved by the IoT wireless technologies. Users can control anytime by the terminal of internet which can be introduced to the field devices of agriculture with all kinds of remote control switch. Shi et al. (2016) pointed out that the IoT system has provided the new way to access the information of agriculture for the farm. In this sense, the IoT has provided a change for the remote monitoring the disease of plants and insect pests in the agriculture field area.

Table 1. Challenges, Opportunities and Use of IoT applications in the Agricultural Sector Source: Author

\begin{tabular}{|c|c|c|}
\hline Challenges of IoT in Agriculture & Opportunities of IoT in Agriculture & Use of IoT in various Agricultural Applications \\
\hline Software Complexity: & Low power Wireless Sensor: & Sensing of Crop: \\
\hline $\begin{array}{l}\text { Software complexity, spatiality and } \\
\text { dynamics are affecting the quality and } \\
\text { production of crop }\end{array}$ & $\begin{array}{l}\text { The low energy consumption of sensors is act } \\
\text { as the main key to support the independent } \\
\text { battery powered devices in a longer flow }\end{array}$ & $\begin{array}{l}\text { The soil moisture sensor and temperature sensor } \\
\text { has played an important role in developing } \\
\text { an automation system in farming field. }\end{array}$ \\
\hline Venkataramana and Padmavathamma (2012) & IEC (2014; Sen, 2009) & Kumar and Ravi (2016) \\
\hline Security: & Better Connectivity: & Managing and Controlling: \\
\hline $\begin{array}{l}\text { Front-end sensors and equipment, network } \\
\text { and back-end of IT systems are referred as } \\
\text { the security threats of IoT. }\end{array}$ & $\begin{array}{l}\text { M2M connectivity services have helped the } \\
\text { farmers to improve the efficiency of } \\
\text { farming operations }\end{array}$ & $\begin{array}{l}\text { The IoT based RFID has improved the } \\
\text { agriculture product quality by managing and } \\
\text { controlling. }\end{array}$ \\
\hline Kumar and Patel (2014) & OECD, 2016 & Sarkar and Chanakal (2016) \\
\hline Technical Skill Requirement: & Operational Efficiency: & Mapping and Monitoring the Croplands Pattern: \\
\hline $\begin{array}{l}\text { The technical skill requirement is needed for } \\
\text { farming and the lack of operating skills creates } \\
\text { an impact on the overall performance in farming }\end{array}$ & $\begin{array}{l}\text { Maintenance of timely scheduling equipment } \\
\text { has enabled a greater operational efficiency } \\
\text { in agricultural sectors }\end{array}$ & $\begin{array}{l}\text { Zigbee and GPS technologies of IoT are paved } \\
\text { the way to monitor the cropland pattern. } \\
\text { Channe et al. }(2015)\end{array}$ \\
\hline Chikaire et al. (2015; Rivera, 2000) & & \\
\hline Lack of Supporting Infrastructure: & Remote Management: & Monitoring of Environment. \\
\hline $\begin{array}{l}\text { Lack of information infrastructure facilities } \\
\text { of IoT has created the negative impact in } \\
\text { productivity of farming. }\end{array}$ & $\begin{array}{l}\text { Remote monitoring computer has allowed } \\
\text { the user to remotely monitor the conditions } \\
\text { of irrigation in the field. }\end{array}$ & $\begin{array}{l}\text { Real-time remote monitoring and management } \\
\text { has achieved by the IoT wireless technologies } \\
\text { successfully. }\end{array}$ \\
\hline Pundir et al. (2016) & Bedekar and Mechkul (2015) & Advantech (2015) \\
\hline
\end{tabular}


The automation has played a vital role in contemporary agriculture. Wireless sensor and remote system has monitored the parameters of environment in the poultry farm (Welbourne et al., 2009). Remote monitoring has achieved by acquiring all values of sensor and this can also viewed later in Google spreadsheets. IoT can be used in farming to manage the level of temperature, humidity and water remotely (Goud and Sudharson, 2015). Remote monitoring computer has allowed the user to remotely monitor the conditions of irrigation in the field. It has also achieved via GPRS system ( Bedekar and Mechkul, 2015).

\section{Research Methodology}

Research is the process of collecting data and information for the purpose of taking business decisions and to frame research method. This research makes use of Interpretivism as the research paradigm and qualitative approach is used in research approach. According to Churchill and Lacobucci (2009), a good review is the one that is conducted and classified based on the time period over which a particular research concept has evolved. This study is a review based one and papers selected are based on the year of publication and separated into themes.

Data is the main part in research that completes the research. Data is divided into primary data and secondary data. Primary data is hand-in-hand collected by the researcher for the purpose of the research and it does not include any fake information. Whereas secondary data is collected from various other sources like websites, articles, publications etc. The present research makes use of only the Secondary data and that was collected from various research articles and research papers. The data is collected based on the year of publication and based on theme of the research. This research makes use of secondary sources that have been gathered from existing academic literature such as journals, books, articles, magazines, internet, newsletter, company publications and whitepapers. The secondary data collected in qualitative form has been subject to Thematic Content Analysis. Thematic content analysis is one in which the research findings are classified into themes and the data is segregated according to the themes (Denscombe 2007). Various applications of IoT in agriculture in this research include crop sensing, mapping and monitoring the croplands pattern, managing and controlling with the help of radio frequency identification and real-time monitoring of environment.

The study includes validation measures and ethical considerations along with the data collection methods.

\section{Research Findings and Proposed Framework}

Figure 1 depicts about challenges and opportunities associated with the applications of internet of things with specific reference to agricultural sector. Variables selected for propositions from the challenges associated with the applications of internet of things with respect to agricultural sector are software complexity, security, technical skill requirement and lack of supporting infrastructure. Variables selected for propositions from the opportunities associated with the applications of internet of things with specific reference to agricultural sector are low power wireless sensor, better connectivity, operating efficiency and remote management.

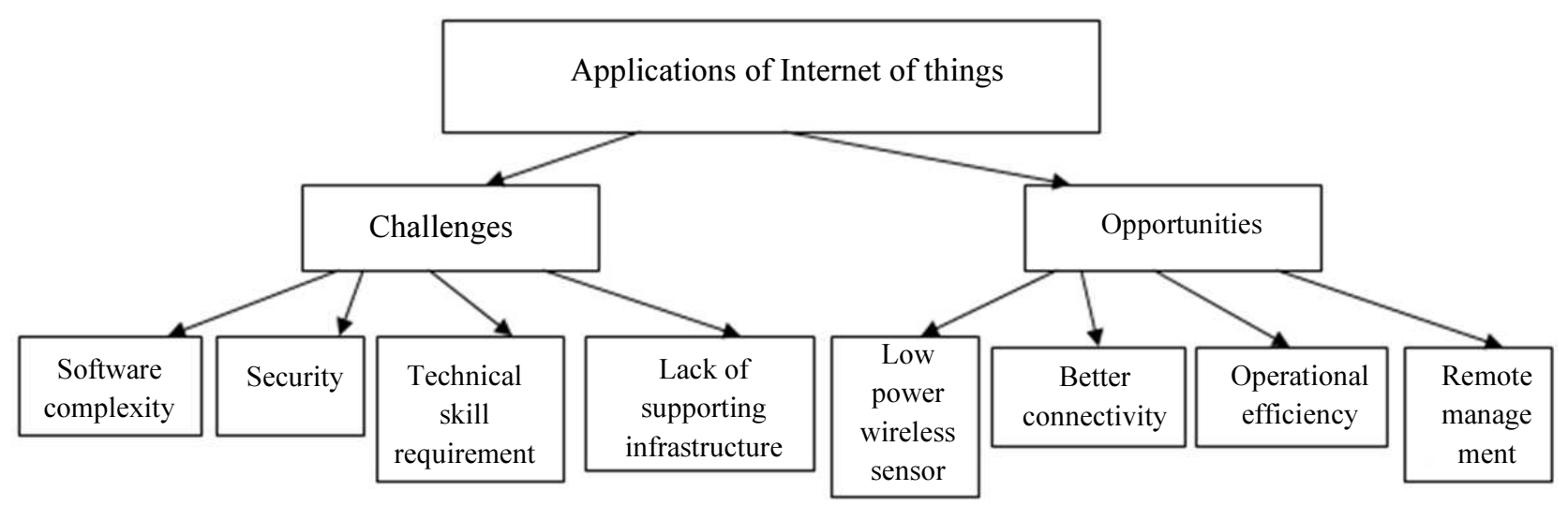

Fig. 1:Proposed Framework for Challenges and Opportunities associated with the Application of IoT in Agriculture; Source: Author 
Propositions of the study are as follows:

P1: Software complexity stands as a challenge in implementing the applications of internet of things with specific reference to agricultural sector

P2: Security stands as a challenge in implementing the applications of internet of things with specific reference to agricultural sector

P3: Technical skill requirement stands as a challenge in implementing the applications of internet of things with specific reference to agricultural sector

P4: Lack of supporting infrastructure stands as a challenge in implementing the applications of internet of things with specific reference to agricultural sector

P5: Low power wireless sensor stands as an opportunity in implementing the applications of internet of things with specific reference to agricultural sector

P6: Better connectivity stands as an opportunity in implementing the applications of internet of things with specific reference to agricultural sector

P7: Operational efficiency stands as an opportunity in implementing the applications of internet of things with specific reference to agricultural sector

P8: Remote management stands as an opportunity in implementing the applications of internet of things with specific reference to agricultural sector

From the above literature, it is evident that software complexity, lack of supporting infrastructure, security and technical skill requirement are some of challenges associated with internet of things applications with respect to agricultural sector. It was noticed that complexity of software, dynamics and spatiality affects the crop's quality and production. However, it was also noted that lack of operating skills has created an impact on the overall farming performance thus technical skill is mainly needed for farming. Lack of supporting infrastructure has created the negative impact in farming productivity. Remote management, operational efficiency, better connectivity and low power wireless sensor are some of the opportunities associated with internet of things applications with special reference to agricultural sector. In terms of opportunities, low energy consumption of sensors support the independent battery powered devices for longer time. Machine to machine connectivity services assist the farmers to enhance the efficiency of operating in terms of farming. Maintaining the timely scheduling equipment allowed greater operational efficiency especially in agricultural sectors. Remote management has permitted the user to monitor the irrigation condition in the field. Applications of internet of things can be used in many areas related to agricultural field namely sensing of crop, real-time monitoring of environment, managing and controlling (use of radio frequency identification) and mapping and monitoring the croplands pattern. Temperature sensor and soil moisture sensor plays a key role in introducing an automation system in farming field that is sensing of crop. Internet of things based radio frequency identification has enhanced the quality of agricultural product by managing and controlling. Global positioning system and Zigbee technologies in the internet of things have paved the way for monitoring the pattern of cropland. At the same time, it was also clear from the above literature that, with the help of internet of things technologies, real-time remote monitoring and management can be achieved.

\section{Discussion and Conclusion}

Internet of things in agricultural field has become one of the most remarkable developing fields in machine-tomachine space. In the present scenario, conservationists, ranchers and farmers require a method to efficiently adopt and conserve resources. Better and efficient way to perform this by utilizing machine to machine communication and actionable data which makes the ongoing data collection very affordable and simple. Internet of things had transformed the agricultural sector and enabled farmers to compete with massive issues they face. This research collects data from the second handed or secondary sources. Secondary data were gathered from different existing academic literature from reputed journals, books, newsletters, magazines, whitepapers and so on. The main purpose of this paper is to review the various challenges and opportunities associated with the applications of internet of things in agricultural sector. Some of the challenges were taken into consideration for reviewing the applications of internet of things are software complexity, security, lack of supporting infrastructure and technical skill requirement. It is clear from the literature that, complexity in the software has to be rectified in order to support the IoT network. Therefore software must be developed as user-friendly for improving the farming, production and quality of the crop. Security is the major threat in the IoT applications. Security has to be enhanced through proper access control, data confidentiality and user authentication. Technical skill is required for farming to enhance the organizational abilities and to perform the farming functions, solving problems and more. Better supporting infrastructure can be developed with proper internet availability and connectivity. Some of the opportunities were taken for reviewing the applications of internet of things are low power wireless sensor, better connectivity, operational efficiency and remote management. Low cost and low power wireless sensor technology are appropriate one to replace wires as communication medium in the agricultural sector. Better internet connectivity services assisted the farmers in enhancing the farming operations efficiency. Internet of things can collect data which optimize operational 
efficiency and can minimize the impact on environment to a great extent. Remote system and wireless sensors will monitor the parameters and manage the level of water, temperature and humidity. Some of the applications of internet of things which can be adopted in agriculture industry are reviewed in this research they are crop sensing, mapping and monitoring the croplands pattern, managing and controlling with the help of radio frequency identification and real-time monitoring of environment.

\section{Recommendations for Future Research}

Intervention of internet of things in development can enhance the efficiency that is achieved similar impacts levels with fewer resources or/and improve effectiveness that is maximize the impact with similar existing resources levels. Moreover, it can be recommended that with advanced development, interventions of internet of things can assist in enhancing public policy, research, monitoring and estimating the programs and basic delivery of service across a wide range of various fields. This research will be an eye-opener for future researchers, academicians, practitioners to know about the challenges and opportunities associated with the applications of internet of things in the agricultural sector. In future, other investigators can expand this research in a quantitative way of approach. On the basis of research framework, future researchers can derive the proposed propositions to test and experiment. Propositions derived in this research can be hypothetically tested by collecting primary data from respondents belonging to agricultural sector and can apply statistical tools on gathered data by the future researchers. Future work can be conducted quantitatively for investigating the challenges and opportunities associated with the applications of internet of things in agricultural sector and variables selected for challenges are software complexity, security, technical skill requirement and lack of supporting infrastructure and variables selected for opportunities are low power wireless sensor, better connectivity, operational efficiency and remote management. At the same time, future work can be carried out in quantitative manner to investigate the challenges and opportunities associated with the applications of internet of things belonging to any field namely information technology, management, industrial sector and so on.

\section{Funding Information}

The authors have no support or funding to report.

\section{Author's Contributions}

Sarfraz Fayaz Khan: Conceptualization, Research framework analysis.

Mohammed Yusoof Ismail: Review of literature analysis drafting.

\section{Ethics}

This article is original and contains unpublished material. The corresponding author confirms that all of the other authors have read and approved the manuscript and there are no ethical issues involved.

\section{References}

Abomhara, M and G.M. Koien, 2014. Security and privacy in the internet of things: Current status and open issues. Proceedings of the International Conference on Privacy and Security in Mobile Systems, May 11-14, IEEE Xplore Press, Aalborg, Denmark, pp: 1-8.

DOI: 10.1109/PRISMS.2014.6970594

Advantech, 2015. Intelligent agricultural solutions.

Anam, S.M. and M. Devender, 2015. A low cost internet of things network for contamination detection in drinking water systems using raspberry pi. Int. J. Electr. Electr. Comput. Sci. Eng., 2: 49-53.

Anusha, P. and K.R. Shobha, 2015. Design and implementation of wireless sensor networks for precision agriculture. Int. J. Scientific Eng. Applied Sci.

Ashton, K., 2009. That-Internet of Things. RFiD J.

Balamurugan, S., N. Divyabharathi, K. Jayashruthi, M. Bowiya and R.P. Shermy et al., 2016. Internet of agriculture: Applying IoT to improve food and farming technology. Int. Res. J. Eng. Technol., 03: 713-719.

Bandyopadhyay, D. and J. Sen, 2011. Internet of things: Applications and challenges in technology and standardization. Wireless Personal Commun., 58: 49-69. DOI: 10.1007/s11277-011-0288-5

Bangera, T., A. Chauhan, H. Dedhia, R. Godambe and M. Mishra, 2016. IoT based smart village. Int. J. Eng. Trends Technol., 32: 301-305. DOI: 10.14445/22315381/IJETT-V32P259

Barath, K.G.K., S.G. Abhishek and S. Malarvizhi, 2016. Development of low power and cost effective unified wireless sensor node-SRM sense for precision agriculture. IJCTA, 9: 7179-7186.

Barakat, S.M., 2016. Internet of things: Ecosystems and applications. J. Current Res. Sci., 4: 32-34.

Bedekar, S.S. and M.A. Mechkul, 2015. IoT based automated irrigation system. Int. J. Modern Trends Eng. Res., 2: 1532-1538.

Bidua, K.R. and C.N. Patel, 2015. Internet of things and cloud computing for agriculture in India. Int. J. Innovative Emerg. Res. Eng., 2: 27-30.

Bo, Y. and H. Wang, 2011. The application of cloud computing and the internet of things in agriculture and forestry. Proceedings of the International Joint Conference on Service Sciences, May 25-27, IEEE Xplore Press, Taipei, Taiwan, pp: 168-172.

DOI: 10.1109/IJCSS.2011.40 
Borgohain, T., U. Kumar and S. Sanyal, 2015. Survey of security and privacy issues of internet of things. Int. J. Adv. Netw. Applic., 6: 2372-2378.

Buckely, J., 2006. The Internet of Things: From RFID to the Next-Generation Pervasive Networked Systems. 1st Edn., Auerbach Publications, New York.

Cai, K., 2012. Internet of things technology applied in field information monitoring. Adv. Inform. Sci. Service Sci., 4: 405-414.

Domingo, M.C., 2012. An overview of the internet of things for people with disabilities. J. Netw. Comput. Applic., 35: 584-96. DOI: $10.1016 /$ j.jnca.2011.10.015

Channe, H., S. Kothari and D. Kadam, 2015. Multidisciplinary model for smart agriculture using Internet-of-Things (IoT), sensors, cloud-computing, mobile-computing and big-data analysis. IJCTA, 6: 374-382.

Chen, Y.K., 2012. Challenges and opportunities of internet of things. Proceedings of the 17th Asia and South Pacific Design Automation Conference, Jan. 30-Feb. 2, IEEE Xplore Press, Sydney, NSW, Australia, pp: 383-388.

DOI: 10.1109/ASPDAC.2012.6164978

Chikaire, J.U., A.O. Ani, C.N. Atoma and A.R. Tijjani, 2015. Capacity building: Key to agricultural extension survival. Scholars J. Agric. Vet. Sci., 2: 13-21.

Churchill, G.A. and D. Lacobucci, 2009. Marketing Research: Methodological Foundations. 10th Edn., Cengage Learning, Mason, ISBN-10: 0324359950, pp: 624.

Datta, S.K., C. Bonnet and N. Nikaein, 2014. An IoT gateway centric architecture to provide novel M2M services. Proceedings of the IEEE World Forum on Internet of Things, Mar. 6-8, IEEE Xplore Press, Seoul, South Korea, pp: 514-519. DOI: 10.1109/WF-IoT.2014.6803221

Devi, V.V. and G. MeenaKumari, 2013. Real-time automation and monitoring system for modernized agriculture. Int. J. Rev. Res. Applied Sci. Eng., 3: 7-12.

Denscombe, M., 2007. The Good Research Guide. 1st Edn., Mc-Graw Hill International, USA, p: 173.

Doknic, V., 2014. Internet of things greenhouse monitoring and automation system.

Dursun, M. and S.A. Ozden, 2011. A wireless application of drip irrigation automation supported by soil moisture sensors. Scientific Res. Essays, 6: 1573-1582.

Elfrink, W., 2014. The internet of things: Capturing the accelerated opportunity. Cisco Blog.

Fangquan, A.M., 2012. Smart planet and sensing china analysis on development of IoT [J]. Agric. Netw. Inform., 12: 5-7.
Farooq, M., M. Waseem, A. Khairi and S. Mazhar, 2015. A critical analysis on the security concerns of Internet of Things (IoT). Perception, 111: 1-6. DOI: $10.5120 / 19547-1280$

FCCI, 2007. Emerging skill shortages in the Indian industry. Federation of Indian Chambers of Commerce and Industry.

Fernandes, P., A. Monteiro and S.A. Lasrado, 2016. Evolution of Internet of Things (Iot): Security challenges and future scope. Int. J. Latest Trends Eng. Technol.

Goud, K.S. and A. Sudharson, 2015. Internet based smart poultry farm. Ind. J. Sci. Technol., 8: 1-5.

GSMA, 2015. Agricultural Machine-to-Machine (Agri M2M): A platform for expansion. GSMA Intelligence, London.

Guang, Y., G. Guining, D. Jing, L. Zhaohui and H. He, 2011. Security threats and measures for the Internet of Things. J. Tsinghua Univ., 51: 1335-1340.

Gubbi, J., R. Buyya, S. Marusic and M. Palaniswami, 2013. Internet of Things (IoT): A vision, architectural elements and future directions. Future Generat. Comput. Syst., 29: 1645-1660. DOI: 10.1016/j.future.2013.01.010

Gutierrez, J., J.F. Villa-Medina, A. Nieto-Garibay and M.A. Porta-Gandara, 2014. Automated irrigation system using a wireless sensor network and GPRS module. IEEE Trans. Instrument. Measur., 63: 166-176. DOI: 10.1109/TIM.2013.2276487

IEC, 2014. Internet of things: Wireless sensor networks. International Electro-Technical Commission, Switzerland.

Abdul Aziz, M.H.H.I.D., M.J. Ismail, M. Mehat and N.S. Haroon, 2009. Remote monitoring in agricultural greenhouse using wireless sensor and Short Message Service (SMS). Int. J. Eng. Technol., 9: 35-43.

Jacobs, P. and T. Hart, 2012. Skills development in rural areas-a brief review of evidence.

Jaishetty, S.A. and R. Patil, 2016. IoT sensor network based approach for agricultural field monitoring and control. Int. J. Res. Eng. Technol., 5: 45-48.

Jayavardhana, G., B. Rajkumar, S. Marusic and M. Palaniswami, 2013. Internet of Things (IoT): A vision, architectural elements and future directions. Future Generat. Comput. Syst., 29: 1645-1660. DOI: 10.1016/j.future.2013.01.010

Jagdale, T. and M.B. Mali, 2016. Greenhouse wireless network monitoring and management using IoT. Int. J. Innovative Res. Electr. Electr. Instruments Control Eng.

Jiang, D. and C. ShiWei, 2010. A study of information security for M2M of IoT. Proceedings of the 3rd International Conference on Advanced Computer Theory and Engineering, Aug. 20-22, IEEE Xplore Press, Chengdu, China, pp: 576-579. DOI: 10.1109/ICACTE.2010.5579563 
Jin, J., J. Gubbi, S. Marusic and M. Palaniswami, 2014. An information framework for creating a smart city through internet of things. IEEE Internet Things J., 1: 112-121. DOI: 10.1109/JIOT.2013.2296516

Kang, C., S. Hwang and J. Moon, 2015. An effect of IoT based Electronic Sow Feeder (ESF) on productivity of swine farms. J. Agric. Inform., 6: 102-107. DOI: $10.17700 /$ jai.2015.6.4.235

Kansara, K., V. Zaveri, S. Shah, S. Delwadkar and K. Jani, 2015. Sensor based automated irrigation system with IoT: A technical review. Int. J. Comput. Sci. Inform. Technol., 6: 5331-5333.

Kao, C. and H.T. Lee, 1998. Demand for industrial management manpower in Taiwan. Int. J. Manpower, 19: 592-602. DOI: $10.1108 / 01437729810242253$

Keerthi, V. and G.N. Kodandaramaiah, 2015. Cloud IoT based greenhouse monitoring system. Int. J. Eng. Res. Applic., 5: 35-41.

Kumar, J.S. and D.R. Patel, 2014. A survey on internet of things: Security and privacy issues. Int. J. Comput. Applic., 90: 20-26.

Kumar, M.K. and K.S. Ravi, 2016. Automation of irrigation system based on Wi-Fi technology and IoT. Ind. J. Sci. Technol., 9: 1-5. DOI: $10.17485 / \mathrm{ijst} / 2016 / \mathrm{v} 9 \mathrm{i} 17 / 93048$

Lee, M., J. Hwang and H. Yoe, 2013. Agricultural production system based on IoT. Proceedings of the IEEE 16th International Conference on Computational Science and Engineering, Dec. 3-5, IEEE Xplore Press, Sydney, NSW, Australia, pp: 833-837. DOI: $10.1109 /$ CSE.2013.126

Li, C. and Y. Guo, 2014. Study and design of agricultural informationization based on internet of things. J. Chem. Pharmacitical Res., 6: 1625-1630.

Liu, J. and L. Yang, 2011. Application of internet of things in the community security management. Proceedings of the 3rd International Conference on Computational Intelligence, Communication Systems and Networks, Jul. 26-28, IEEE Xplore Press, Bali, Indonesia, pp: 314-318. DOI: $10.1109 /$ CICSyN.2011.72

Madakkam, S., R. Ramaswamy and S. Tripathi, 2015. Internet of Things (IoT): A literature review. J. Comput. Commun., 3: 164-173. DOI: $10.4236 /$ jcc.2015.35021

Mehta, A. and S. Patel, 2016. IoT based smart agriculture research opportunities and challenges. Int. J. Technol. Res. Eng., 4: 541-543.

Menon, B.G., B. Mahanty and D.R. Rao, 2012. Assessment of technical manpower requirements in agriculture sector in India.
Miazi, M.N.S., Z. Erasmus, M.A. Razzaque, M. Zennaro and A. Bagula, 2016. Enabling the internet of things in developing countries: Opportunities and challenges. Proceedings of the 5th International Conference on Informatics, Electronics and Vision, May 13-14, IEEE Xplore Press, Dhaka, Bangladesh, pp: 564-569. DOI: 10.1109/ICIEV.2016.7760066

More, S.N. and M. Nighot, 2016. A review of wireless sensor network for agriculture. Int. J. Recent Innovat. Trends Comput. Commun., 4: 110-113.

Nandurkar, S.R., V.R. Thool and R.C. Thool, 2014. Design and development of precision agriculture system using wireless sensor network. proceedings of the 1st International Conference on Automation, Control, Energy and Systems, Feb. 1-2, IEEE Xplore Press, Hooghy, India, pp: 1-6. DOI: $10.1109 /$ ACES.2014.6808017

OECD, 2016. The internet of things: Seizing the benefits and addressing the challenges.

Oracle, 2015. Improving agribusiness performance with big data architect's guide and reference architecture introduction. Oracle Corporation, USA.

Osborn and Charlie, 2014. Future of the enterprise: Heavy investment in internet of things security. ZDNet.

Pande, P. and A.R. Padwalkar, 2014. Internet of things-a future of internet-a survey. Int. J. Adv. Res. Comput. Sci. Manage. Stud.

Parameswaran, G. and K. Sivaprasath, 2016. Arduino based smart drip irrigation system using internet of things. Int. J. Eng. Sci. Comput., 6: 5518-5521. DOI: $10.4010 / 2016.1348$

Patil, V.C., K.A. Al-Gaadi, D.P. Biradar and M. Rangaswamy, 2012. Internet of Things (IoT) and cloud computing for agricultural: An overview. Proceedings of the Agro-Informatics and Precision Agriculture, (AIPA' 12), India, pp: 292-296.

Paventhan, A., 2013. Internet of things based approach to agriculture monitoring.

Pavana, N.R. and M.C. Padma, 2016. Design of low cost system for real time monitoring of water quality parameters in IoT environment. Int. J. Adv. Res. Comput. Sci. Manage. Stud.

Perera, C., C.H. Liu and S. Jayawardena, 2015. The emerging internet of things marketplace from an industrial perspective: A survey. IEEE Trans. Emerg. Top. Comput., 3: 585-598. DOI: 10.1109/TETC.2015.2390034

Podder, S. and N. Kuntagod, 2016. Smart services: Designing internet of things solutions for aspiring smart nations. Accenture Bus. J. India.

Pundir, Y., N. Sharma and Y. Singh, 2016. Internet of Things (IoT): Challenges and future directions. Int. J. Adv. Res. Comput. Commun. Eng., 5: 960-964. DOI: $10.17148 /$ IJARCCE.2016.53226 
Sun, Q.B., J. Liu, S. Li, C.X. Fan and J.J. Sun, 2010. Internet of things: Summarize on concepts, architecture and key technology problem. J. Beij. Univ. Posts Telecommun., 33: 1-9.

Qin, P., Z. Lu and T. Zhu, 2015. Application research on agricultural production throughout the internet. Proceedings of the 3rd International Conference on Management, Education and Information and Control, (EIC' 15).

Raigonda, M.R., V.S. Valsang and M.S. Valsang, 2016. An IoT based framework for group monitoring and irrigation control. Int. J. Eng. Comput. Sci., 05: 17815-17818. DOI: $10.18535 / \mathrm{ijecs} / \mathrm{v} 5 \mathrm{i} 9.02$

Rivera, W.M., 2000. The changing nature of agricultural information and the conflictive global developments shaping extension. Eur. J. Agric. Educ. Extens., 7: 31-41. DOI: $10.1080 / 13892240008438803$

Roman, R., P. Najera and J. Lopez, 2013a. Securing the internet of things. Computer, 44: 51-58. DOI: 10.1109/MC.2011.291

Roman, R., J. Zhou and J. Lopez, 2013b. On the features and challenges of security and privacy in distributed internet of things. Comput. Netw., 57: 2266-2279. DOI: 10.1016/j.comnet.2012.12.018

Romeo, S., 2016. Enabling smart farming through the internet of things current status and trends.

Rose, K., S. Eldridge and L. Chapin, 2015. The internet of things: An overview. Internet Society, Switzerland.

Roshan, R. and A.K. Ray, 2016. Challenges and risk to implement IoT in smart homes: An Indian perspective. Int. J. Comput. Applic., 153: 16-19. DOI: $10.5120 /$ ijca2016911982

Sarkar, P.J. and S. Chanagala, 2016. A survey on IoT based digital agricultural monitoring system and their impact on optimal utilization of resources. IOSR J. Electr. Commun. Eng., 11: 01-04. DOI: $10.9790 / 2834-11120104$

Schimek, R.S., 2016. IoT case studies: Companies leading the connected economy. American International Group.

Sharma, D., A.P. Bhondekar, A. Ojha and C. Ghanshyam, 2016. A technical assessment of IoT for Indian agriculture sector. Int. J. Comput. Applic.

Shao, W. and L. Li, 2009. Analysis of the development route of IoT in China. Perking: China Sci. Technol. Inform., 24: 330-331.

Shankland and Stephen, 2014. How the internet of things knows where gunfire happens. cnet.com.

Sen, J., 2009. A survey on wireless sensor network security. Int. J. Commun. Netw. Inform. Security, 1: 55-78.

Soumyalatha and S.G. Hegde, 2015. Study of IoT: Understanding IoT architecture. applications, issues and challenges. Int. J. Adv. Netw. Applic.

Tongke, F., 2013. Smart agriculture based on cloud computing and IoT. J. Convergence Inform. Technol. DOI: 10.4156/jcit.vol8.issue2.26
Venkataramana, K. and M. Padmavathamma, 2012. A design of framework for agri-cloud. IOSR J. Comput. Eng., 4: 01-06.

Vermesan, O. and P. Friess, 2013. Internet of Things: Converging Technologies for Smart Environments and Integrated Ecosystems. 1st Edn., River Publishers, Denmark, ISBN-10: 8792982735, pp: 364.

Wang, X. and N. Liu, 2014. The application of internet of things in agricultural means of production supply chain management. J. Chem. Pharmaceutical Res., 6: 2304-2310.

WEF, 2015. Industrial internet of things: Unleashing the potential of connected products and services. World Economic Forum, Switzerland.

Welbourne, E., L. Battle, G. Cole, K. Gould and K. Rector et al., 2009. Building the Internet of Things using RFID. IEEE Internet Comput., 13: 48-55. DOI: $10.1109 /$ MIC.2009.52

Wind, 2016. Going green with the internet of things. Wind River Inc.

$\mathrm{Wu}, \mathrm{Z}$., S. Li, M. Yu and J. Wu, 2015. The actuality of agriculture internet of things for applying and popularizing in China. Proceedings of the International Conference on Advances in Mechanical Engineering and Industrial Informatics, (EII' 15).

Whitmore, A., A. Agarwal and L.D. Xu, 2015. The internet of things-a survey of topics and trends. Inform. Syst. Front., 17: 261-274. DOI: $10.1007 / \mathrm{s} 10796-014-9489-2$

Yan-e, D., 2011. Design of intelligent agriculture management information system based on IoT. Proceedings of the International Conference on Intelligent Computation Technology and Automation, Mar. 28-29, IEEE Xplore Press, China, pp: 1045-1049. DOI: 10.1109/ICICTA.2011.262

Yin, W., 2017. Implementation of IoTs in agriculture industry in China. China Communications Services Corporation Limited.

Zhang, M., G. Chen and L. Gao, 2013. An Intellignt irrigation system based on wireless sensor network and fuzzy control. J. Netw., 5: 1080-1087.

Zhao, K. and L. Ge, 2013. A survey on the internet of things security. Proceedings of the 9th International Conference on Computational Intelligence and Security, Dec. 14-15, IEEE Xplore Press, Leshan, China, pp: 663-667. DOI: 10.1109/CIS.2013.145

Zhao, J. and G. Wang, 2014. Research on adopting application in agricultural products supply chain based on internet of things. BioTechnol.- Ind. J., 10: 16256-16266. DOI: $10.2174 / 1874110 X 014080101108$

Zhou, L., Q. Wen and H. Zhang, 2012. Preserving sensor location privacy in internet of things. Proceedings of the 4th International Conference on Computational and Information Sciences, Aug. 17-19, IEEE Xplore Press, Chongqing, China, pp: 856-859. DOI: 10.1109/ICCIS.2012.210 